\title{
LA CHISPA DE LA RIMA: RASGOS DE ORALIDAD EN LA POESÍA ESPAÑOLA RECIENTE*
}

\author{
Susana RodRíguez RosiQUe \\ Universidad de Alicante (España) \\ Luis BAgué Quílez \\ Universidad de Murcia (España)
}

\section{RESUMEN}

El objetivo de este artículo consiste en proponer un nuevo tipo de oralidad: la oralidad estética, que puede rastrearse en el programa creativo de los textos poéticos contemporáneos. Frente al carácter recreador de la oralidad fingida y la orientación persuasiva de la oralidad simuladora de realidad, esta nueva modalidad no se extrae directamente de la realidad circundante, sino que aparece filtrada a través de diversos códigos mediáticos. En este trabajo se analizará, en concreto, cómo la oralidad llega a los poemas mediatizada por el discurso publicitario. Para desvelar esta red de relaciones, se analiza el papel que desempeña el conocimiento compartido en cualquier clase de interacción y cómo la publicidad forma parte de ese conjunto de información. Asimismo, se revisan los textos adscritos a la oralidad creadora y se establece una tipología que vincula la oralidad con el proceso creativo. Finalmente, se destaca la función desmitificadora de la oralidad estética.

PALABRAS CLAVE: oralidad creadora; conocimiento compartido; discurso publicitario; intermedialidad; poesía contemporánea.

\section{AbSTRACT}

The aim of this paper is to propose a new kind of orality: aesthetic orality, which can be traced in the creative program of contemporary poetic texts. In contrast to the recreative nature of the pretended orality and the persuasive

* Este trabajo se enmarca en el Proyecto de Investigación «Gestión de la información y estructuración lingüística: explicaciones y aplicaciones (GESTINF)» (FFI2017-85441-R), financiado por el Ministerio de Economía, Industria y Competitividad. Asimismo, es un resultado del Programa «Ramón y Cajal» (RYC-2014-15646), concedido por el Ministerio de Economía y Competitividad. 
orientation of the reality-simulating orality, this new modality is not directly extracted from the surrounding reality, but rather appears filtered through media codes. Specifically, this paper deals with the way in which orality emerges in contemporary poetry through advertising discourse. In order to reveal this network of relationships, the role that shared knowledge plays in any kind of interaction and how advertising is part of that set of information are analyzed. Furthermore, the texts ascribed to creative orality are revisited, and a typology linking orality to the creative process is proposed. Finally, the demystifying function of aesthetic orality is outlined.

KEYWORDS: creative orality; shared knowledge; advertising discourse; intermediality; contemporary poetry.

Fecha de recepción: 11/08/2020

\section{Poesía y oralidad: Un VIAJE de IDA y VUElta}

La poesía contemporánea refleja una tensión latente entre la oralidad -que remite a una primigenia recepción auditiva- y la escritura -que se sustenta en la recepción visual de la literatura moderna- (Senabre 1991; Martínez Fernández 1995). La evolución del acto comunitario que implica el recitado en voz alta al acto privado que supone la lectura en silencio no solo incide en la difusión de los textos, sino que determina su propia naturaleza (Paz 1971: 333). Aunque la poesía sigue conservando cierta sonoridad (la huella de un «ritmo sonoro»), desde la aparición de la imprenta la proyección colectiva se irá sustituyendo por la experiencia individual. Este cambio afectará a la identidad de algunos géneros -el teatro, concebido desde entonces como una representación escenificada en lugares acotados, como los corrales de comedias (Senabre 1986: 109; Martínez Fernández 1995: 230-231) - y comprometerá la pervivencia de otros -la épica, ligada desde sus orígenes a una raíz oral-. A pesar de que en los siglos XVI y XVII todavía existe una noción de la poesía vinculada a la divulgación oral de los textos, lo que explica el desinterés de algunos autores a la hora de imprimir sus obras, en la era moderna se consolida ya la distribución de roles entre los géneros orales y escritos. Con todo, la poesía lírica incorporará selectivamente elementos de la primitiva oralidad, desde la segmentación del verso (Brioschi y Di Girolamo [1984] 1988: 109), al que se aplican conceptos como los de «armonía», «melodía» o «musicalidad», hasta el recurso nemotécnico de la rima (Núñez Ramos 1992: 116), pasando por fenómenos de repetición como la letanía o el estribillo (Zumthor 1983). Esta situación plantea dos caminos posibles: por un lado, el regreso a la poesía tradicional, que aún perdura en ciertas manifestaciones literarias de carácter coral 
y ascendencia folclórica ${ }^{1}$; por otro, la utilización intertextual de injertos del registro oral en el discurso poético. Esta segunda vía emerge como la más rentable en la comunicación poética contemporánea, al tiempo que exige una participación más activa de los destinatarios, convertidos en cómplices capaces de interpretar distintos tipos de textos y géneros de discurso (Narbona 2009: 116).

El análisis de esta segunda vía requiere determinar el papel que juega la oralidad en la comunicación literaria. En este sentido, se ha hablado de «oralidad fingida» (Brumme 2008, 2012), «oralidad simulada» (Mancera 2009) o «mímesis de la oralidad» (López Serena 2007) para definir la técnica mediante la cual se pretenden recrear las características del discurso oral en los textos narrativos. Esta modalidad aspira a extraer quirúrgicamente la oralidad del medio circundante y reformularla para trasplantarla al ámbito literario: se trata de un proceso de transposición (Mancera 2009) que busca explotar el parecido con la realidad mediante una reproducción casi magnetofónica del habla espontánea y coloquial.

Un paso más allá se encuentra la «oralidad simuladora de realidad» (López Serena 2014), que obedece a un proceso de coloquialización estratégica (Briz 2013) y que está asociada a discursos de naturaleza mediática. Frente a la oralidad fingida, la conversación ahora fluye de manera natural, pero se supedita a las restricciones que impone el medio: estamos ante un tipo de oralidad guiada por la situación en la que se produce y sospechosa de subordinarse a las exigencias del guion. Este tipo de oralidad es la que se observa en formatos de telerrealidad -reality shows, como Gran Hermano (López Serena 2014), o tertulias televisadas (Briz 2013)-. En un sentido diferente, igualmente condicionado por el formato, pero con una naturaleza polifónica y multiperspectivista, se situarían aquí las interacciones propias de algunas plataformas de viaje, como Booking o TripAdvisor (Calvi 2019). El objetivo último de la oralidad simuladora de realidad tiene un propósito persuasivo. La dinámica oral contribuye a generar una falsa apariencia de realidad, cuya engañosa autenticidad revierte en la ilusión de verosimilitud que define a los productos manufacturados por la industria de la telerrealidad. A su vez, los comentarios vertidos en foros como los que ofrece TripAdvisor se aproximan a una finalidad persuasiva en dos sentidos: por un lado, como en la telerrealidad, se apoyan en una falsa sensa-

\footnotetext{
${ }^{1}$ No obstante, este itinerario se ha reciclado en diversas e-juglarías que asumen un «rescate de la oralidad» (Scarano 2014: 21), a menudo en compañía de otros recursos -gestualidad teatral, mediación de las nuevas tecnologías-, y que se difunden en foros específicos, como festivales y recitales. En este ámbito se enmarcan formatos como la performance, el spoken word, el poetry slam, la videopoesía, la holopoesía, la perfopoesía o la poesía de generación automática (Jauralde Pou 2014: 25-28; Cullell 2015: 547-561).
} 
ción de cercanía, provocada por la inmediatez que caracteriza al registro oral coloquial; por otro, no debe olvidarse que estamos ante una plataforma de viajes con una orientación de índole comercial.

A medio camino entre la fingida y la simuladora de realidad, se localiza la oralidad en la publicidad actual. Mientras que con la primera comparte la voluntad recreadora y la plantilla imitativa, con la segunda coincide en su afán claramente persuasivo. Ambas se observan en este simulacro de conversación que aparece en el spot Vecineando, de Casa Tarradellas, y que se transcribe a continuación. El predominio de las relaciones paratácticas y el que causal de enunciación; la presencia de marcadores conversacionales como bueno; las constantes rectificaciones y reformulaciones; o el juego entre lo que se dice y lo que se quiere decir en la gestión del significado constituyen mecanismos imprescindibles para recrear la conversación coloquial (Briz 2000: 51; Briz y Grupo Val.Es.Co 2003, 2014; Hidalgo 2002: 9-10; Portolés 2004: 68).

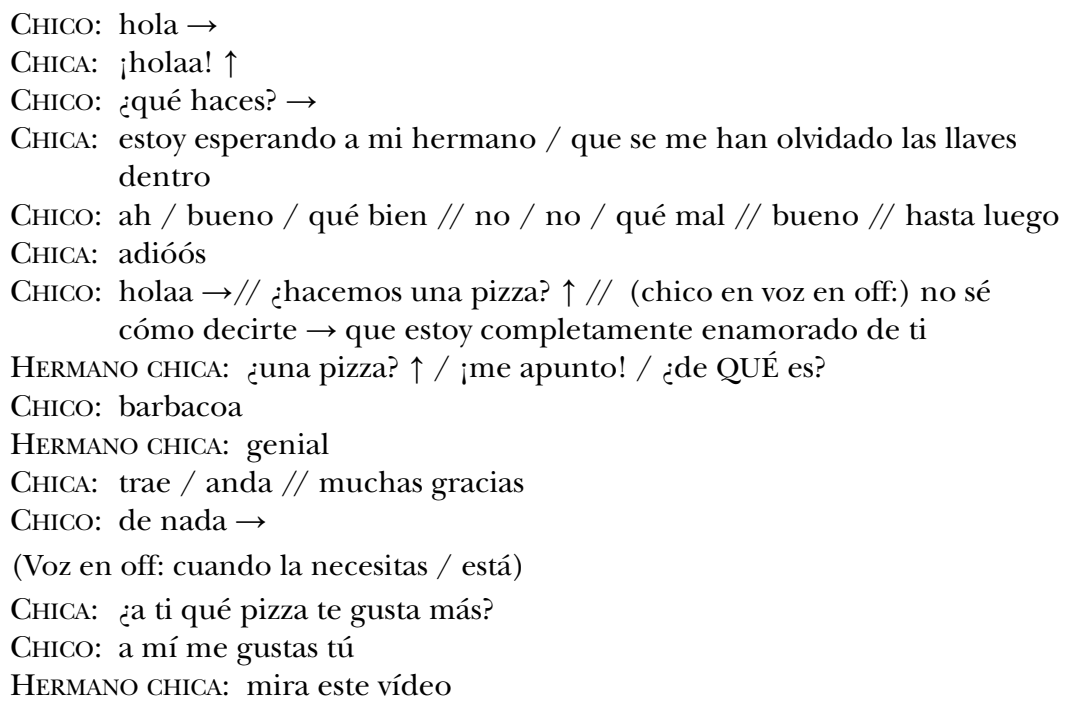

(Voz en off: pizza fresca de casa tarradellas // como en casa / en ningún sitio)

Frente a los modelos anteriores, se erige la oralidad estética, cuya finalidad ya no es meramente recreativa, ni persuasiva, ni siquiera una mezcla de estas, sino creadora, como refleja el esquema que aparece en la Figura 1, en el que se sitúan los distintos tipos de oralidad.

La oralidad que había imperado en la poesía hasta la actualidad respondía a un modelo de confidencia lírica caracterizado por un tono de voz íntimo, como «el discurso de una persona dirigiéndose a otra» (Auden [1962] 1974: 98). Ese andamiaje, que reproduce el par mínimo comuni- 
Figura 1. Tipos de oralidad en discursos derivados

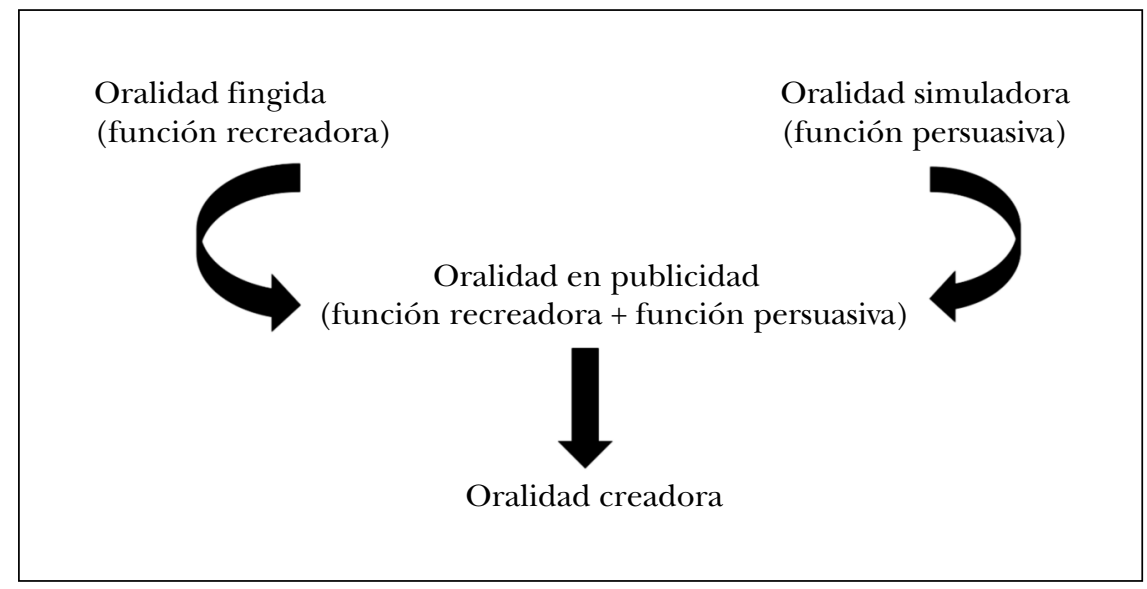

cativo (García Negroni y Tordesillas 2001: 80-87), se corresponde en buena medida con la oralidad mimética que se ha analizado frecuentemente en el ámbito narrativo. Así se advierte también, por ejemplo, en la poética coloquial o conversacional hispanoamericana -uno de cuyos principales exponentes sería Mario Benedetti-, o en las estrategias dialógicas que se aprecian desde la promoción española del medio siglo -donde destaca la figura de Ángel González- hasta la poética de la experiencia que proliferó en los años ochenta. Si el poema de Benedetti «Hagamos un trato» (Preguntas al azar, 1986) está orientado directamente hacia la segunda persona (a la que se interpela mediante el vocativo compañera o el pronombre usted) y se construye como una propuesta que espera una intervención reactiva, en «Eso era amor» (Breves acotaciones para una biografia, 1971), de Ángel González, nos encontramos ante una conversación distorsionada por un sentido del humor rayano en el absurdo (Rodríguez Rosique y Bagué Quílez 2012):

\section{HAGAMOS UN TRATO}

Compañera usted sabe puede contar conmigo no hasta dos o hasta diez sino contar conmigo si alguna vez advierte que la miro a los ojos y una veta de amor reconoce en los míos no alerte sus fusiles ni piense qué delirio a pesar de la veta 


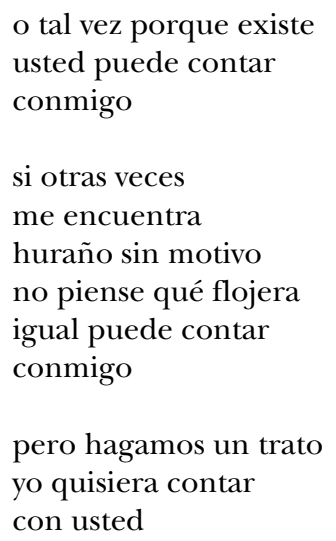

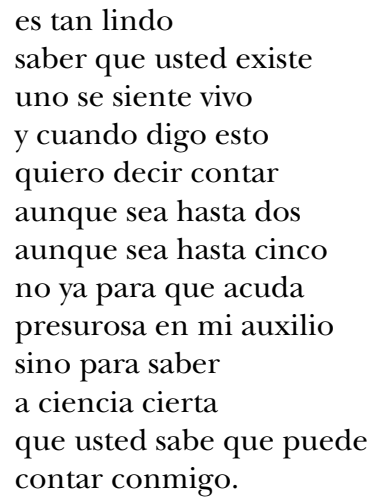

\section{ESO ERA AMOR}

Le comenté:

-Me entusiasman tus ojos.

Y ella dijo:

-Grandes, $-\dot{i}$ Te gustan solos o con rimel?

Respondí sin dudar.

Y también sin dudar me los dejó en un plato $\mathrm{y}$ se fue a tientas.

En contraste con la transparencia de la dinámica conversacional que hallamos en los poemas anteriores, en los que analizaremos a lo largo del presente artículo asistimos a un proceso de transposición desdibujado por la intermedialidad, o la superposición de diversos códigos discursivos. Se diría que este proceso de borrado forma parte del propio programa creativo, como un sampleado que recoge el ruido mediático circundante ${ }^{2}$. La fuente de la que se extrae la oralidad en estos casos no parece provenir directamente de la realidad, sino que está filtrada por otros medios. Esto es lo que ocurre en «La vestal Occia» (Zonas comunes, 2011), de Almudena Guzmán, donde un tema poético grave, como la maternidad, se rebaja mediante un inserto oral que reproduce las palabras de un personaje significativo del famoseo patrio (Belén Esteban), y que fueron propagadas ampliamente por los medios de comunicación hace unos años:

\footnotetext{
${ }^{2}$ Tomando prestado el término del ámbito musical, por «sampleado» entendemos el producto textual en el que confluyen voces simultáneas que pertenecen a diversos universos discursivos.
} 


\title{
LA VESTAL OCCIA
}

\author{
Quizá me habría gustado ser madre, \\ tampoco estoy tan segura, \\ pero siento una cierta nostalgia \\ por lo que solo pueden decir \\ las madres. \\ Andreíta, cómete el pollo.
}

Como decíamos, el lector que se enfrenta a estos textos ha de activar diferentes modelos discursivos en el proceso de interpretación. El objetivo de este trabajo consiste en desvelar cómo funciona este tipo de oralidad estética; específicamente, nos centraremos en aquellos textos que extraen la oralidad del acervo publicitario. Para desentrañar esta maraña de relaciones, el trabajo se organiza de la siguiente manera: en la sección 2 se explica el papel que desempeña el conocimiento compartido en cualquier tipo de interacción y cómo la publicidad forma parte de ese conjunto de información; en la tercera sección se analizan los textos poéticos adscritos a la modalidad de oralidad creadora y se establece una tipología que vincula la oralidad con el acto creativo; finalmente, en la última sección se exponen las conclusiones más relevantes del trabajo, y se destaca la función desmitificadora de la oralidad estética, susceptible de proyectarse sobre diversos niveles.

\section{CONOCIMIENTO COMPARTIDO, PUBLICIDAD Y ORALIDAD}

Para poder reconstruir la oralidad fragmentada que aparece en los textos poéticos contemporáneos es necesario que el lector se apoye en el conocimiento compartido, pues será ahí donde encuentre las claves que le permitan interpretar los distintos niveles con los que juega el poema.

Cualquier interacción comunicativa constituye una actividad conjunta (Levinson 1979; Clark 1996: 18-19); es decir, exige, al menos, dos participantes -estos pueden ser reales o imaginarios, instituciones o individuos- que han de coordinar sus acciones individuales. Las acciones conjuntas que llevan a cabo los participantes en un discurso son acciones comunicativas -o actos de habla (Searle [1969] 1980)-que suponen el encuentro entre la intención del hablante y la interpretación del destinatario (Grice [1957] 1989). A su vez, las sucesivas acciones comunicativas que forman parte de un discurso están puestas al servicio de acciones sociales más amplias, como planear vacaciones o comidas, cotillear, debatir sobre política, hacer negocios, enseñar, entretener o divertir. 
El entorno más básico en el que se lleva a cabo un discurso es la conversación, que adquiere, por tanto, un estatus especial (Fillmore 1981; Chafe 1994: 41; Clark 1996: 8-11). A partir de aquí, cualquier otro tipo de discurso se considera una desviación (Fillmore 1981: 152). La distinción entre la conversación y otros tipos de discurso, además, no se limita únicamente a la establecida entre oralidad y escrituralidad: dentro de la oralidad puede haber diferencias, como la que refleja un debate frente a una entrevista o una tertulia; dentro de los discursos escritos, tampoco es lo mismo un artículo académico, un texto publicitario o una lista de la compra; incluso dentro del mismo discurso, como el que representa un periódico, la sección de noticias no funciona igual que el editorial, las cartas al director, las columnas o las tiras cómicas (Chafe 1994: 48-49). Para dar cuenta de estas diferencias, Clark (1996) propone una serie de parámetros que perfilan distintos tipos de discurso como desviaciones de la conversación oral cara a cara, según se observa en la Tabla 1.

Cada uno de estos entornos, a su vez, puede exhibir más de un nivel de actividad, con sus propios participantes y con una localización específica. El primer nivel siempre representa a gente real haciendo cosas reales. A

TABla 1. Parámetros que definen distintos tipos de discurso como desviaciones a partir del entorno básico (Clark 1996: 8)

\begin{tabular}{lcc}
\cline { 2 - 3 } & Entornos orales & Entornos escritos \\
\hline Entorno personal & Conversación cara a cara & Correo electrónico, wasap \\
\hline Entorno no personal & Clase magistral & Artículo de prensa \\
\hline Entorno institucional & $\begin{array}{c}\text { Interrogatorio de un abogado } \\
\text { a un testigo }\end{array}$ & Carta comercial \\
\hline Entorno prescriptivo & $\begin{array}{c}\text { Casarse (decir sí quiero } \\
\text { en unas circunstancias } \\
\text { concretas) }\end{array}$ & $\begin{array}{c}\text { Firmar un contrato } \\
\text { de compraventa } \\
\text { ante un notario }\end{array}$ \\
\hline Entorno ficcional & $\begin{array}{c}\text { Actor de teatro, } \\
\text { cuentacuentos }\end{array}$ & $\begin{array}{c}\text { Un novelista o un poeta } \\
\text { escriben para los lectores }\end{array}$ \\
\hline Entorno mediatizado & Traducción & $\begin{array}{c}\text { Alguien que escribe una } \\
\text { novela o cualquier otro } \\
\text { discurso para otros } \\
\text { simultánea }\end{array}$ \\
& & $\begin{array}{c}\text { (los discursos oficiales } \\
\text { escritos por otra gente) }\end{array}$ \\
\hline Entorno privado & Hablar con uno mismo & $\begin{array}{c}\text { Escribirse un recordatorio: } \\
\text { apuntarse comprar leche } \\
\text { en la mano o en una nota } \\
\text { pegada en la nevera }\end{array}$ \\
\hline
\end{tabular}


partir de ahí, el nivel real puede ser, por ejemplo, el de un escritor y sus lectores, dentro del cual el autor inserta otros niveles. No obstante, un hablante que actúa como participante en una conversación puede igualmente introducir distintos niveles de actividad en su intervención (por ejemplo, contando un chiste o relatando una anécdota).

Cualquier tipo de actividad conjunta impone un requisito para que sea posible llevarla a cabo: los participantes han de poseer algún tipo de conocimiento compartido antes de verse envueltos en el desarrollo de la actividad. En efecto, cuando la gente toma partido en las conversaciones, trae consigo una serie de conocimientos, creencias, asunciones, o cualquier otro tipo de información, que Stalnaker (1978) denominó Common Ground ['contexto común']. Este tipo de información representa un paso previo imprescindible para la coordinación; por eso los hablantes nos vemos en la necesidad constante de aventurar hipótesis sobre lo que creemos que los destinatarios ya saben (Gutiérrez Ordóñez 1997: 26).

Existen dos tipos de fuentes que alimentan el conocimiento compartido: las comunitarias y las personales (Clark 1996). Las primeras se basan en la existencia de comunidades culturales; de hecho, solemos categorizar a nuestros destinatarios por su nacionalidad, lengua, aficiones o religión para inferir lo que saben, creen o asumen. Una comunidad cultural es, por tanto, un grupo de gente con experiencias compartidas de las que otras comunidades carecen. Dentro de ese conocimiento compartido comunitario se encuentra aquella información que tenemos por el mero hecho de ser humanos: todos experimentamos sensaciones semejantes. A partir de aquí, cada comunidad cultural puede desarrollar un léxico especializado, lo que permite aislar terminologías, argots o jergas. También se situaría en este nivel el conocimiento compartido de determinados acontecimientos culturales, normas de comportamiento, convenciones, habilidades, procedimientos, o incluso experiencias inefables. Las comunidades culturales, como las que se observan en la Tabla 2 (en la página siguiente), se relacionan mediante anidamientos, lo que permite que cada individuo pertenezca simultáneamente a más de una.

El conocimiento compartido personal, por su parte, se basa en experiencias conjuntas, entre las que se pueden diferenciar dos clases: experiencias perceptivas conjuntas y acciones conjuntas (Clark 1996: 112-116). Mientras que el conocimiento compartido comunitario define comunidades culturales, el conocimiento compartido personal se articula en torno al parámetro de la familiaridad: alguien nos resultará más o menos cercano en función de nuestro historial de experiencias conjuntas.

En este entramado de niveles, la publicidad juega un papel importante. Así, los eslóganes (Del Caserío me fío), los textos publicitarios (los comentarios que despierta cada año el anuncio de la lotería de Navidad), incluso 
TABLA 2. El conocimiento compartido basado en comunidades culturales (Clark 1996: 103)

\begin{tabular}{lcc}
\hline $\begin{array}{c}\text { Bases } \\
\text { para la experiencia }\end{array}$ & $\begin{array}{c}\text { Ejemplos } \\
\text { de comunidad }\end{array}$ & $\begin{array}{c}\text { Ejemplos } \\
\text { de experiencias }\end{array}$ \\
\hline Nacionalidad & $\begin{array}{c}\text { Americana, canadiense, } \\
\text { española }\end{array}$ & $\begin{array}{c}\text { Prácticas culturales } \\
\text { de la nación, instituciones }\end{array}$ \\
\hline Formación académica & $\begin{array}{c}\text { Estudiantes universitarios, } \\
\text { estudiantes de Derecho, } \\
\text { estudiantes de secundaria }\end{array}$ & $\begin{array}{c}\text { Contenidos específicos, } \\
\text { competencias formativas }\end{array}$ \\
\hline Etnia & Hispanos, afroamericanos & $\begin{array}{c}\text { Aspectos vinculados } \\
\text { con la herencia cultural, } \\
\text { experiencias y prácticas } \\
\text { propias de la etnia }\end{array}$ \\
\hline Política & $\begin{array}{c}\text { Demócratas, liberales, } \\
\text { socialistas, marxistas }\end{array}$ & $\begin{array}{c}\text { Claves políticas, valores, } \\
\text { figuras políticas }\end{array}$ \\
\hline Subcultura & $\begin{array}{c}\text { Estrellas del rock, } \\
\text { bandas callejeras, } \\
\text { drogodependientes }\end{array}$ & $\begin{array}{c}\text { Códigos underground, } \\
\text { jergas, savoir faire }\end{array}$ \\
\hline Género & Hombres, mujeres, \\
transexuales & $\begin{array}{c}\text { Expresión corporal, } \\
\text { costumbres sociales }\end{array}$ \\
& propias de cada género \\
\hline
\end{tabular}

los personajes que los protagonizan (recuérdese el Hola / soy Edu / Feliz Navidad) o la música que los acompaña (la melodía relajante que pone banda sonora a los anuncios de Nescafé), parecen desmarcarse de sus marcas comerciales para entrar a formar parte del conocimiento compartido de una determinada comunidad cultural: la que surge de la intersección entre la cosmovisión occidental, los valores propios de una clase media con cierto poder adquisitivo y la receptividad a los estímulos de una «sociedad etiquetada» (Ferrer 2002: 77).

El conocimiento compartido se convierte, así, en el eslabón perdido que permite conectar el discurso publicitario - de naturaleza eminentemente persuasiva (Gutiérrez Ordóñez 2002: 262-263) ${ }^{3}$ - con el discurso estético -de naturaleza fundamentalmente expresiva-. Si tradicionalmente la publi-

${ }^{3}$ Esa naturaleza persuasiva es compatible con la propuesta de Charaudeau (2010: 67), para quien el cimiento del discurso publicitario reside en la «incitación a hacer»: cualquier proyecto comunicativo que exija una acción por parte de un destinatario sobre el que no tengamos autoridad suficiente ha de basarse en una serie de estrategias de seducción con la finalidad de construir una ilusión de creencia común. 
cidad ha acudido a la literatura o a la historia del arte para envolver sus productos y dotarlos de cierto prestigio intelectual, lo renovador ahora es que el medio poético recicla las convenciones del código publicitario para llegar al destinatario actual, quitándole gravedad al discurso y añadiéndole unas gotas de inmediatez desenfadada (Bagué Quílez y Rodríguez Rosique 2020: 111-112). La oralidad que aparece en los textos poéticos contemporáneos forma parte, precisamente, del catálogo de recursos que la poesía copia de la publicidad.

\section{CAja DE RESONANCIA: ENTRE El DisCURSO ORAL Y EL PUbliCitARIO}

En este apartado se presentan algunos textos poéticos que ejemplifican la interacción entre las claves del discurso oral y las consignas publicitarias. Esta amalgama permite establecer una tipología discursiva en función del grado de procesamiento que exhiban los ingredientes orales y publicitarios en el desarrollo de los poemas. Para poder interpretarlos correctamente, será necesario desplegar distintos estratos de conocimiento compartido. En este sentido, se puede establecer una escala que iría desde lo más sencillo -la alusión a lo oral en el discurso publicitario, a modo de guiño cómplicehasta otras formulaciones más elaboradas: la apropiación de un formato claramente oral para expresar temas poéticos recurrentes, a través de la espectacularización de la vida privada; o la utilización de marcas comerciales, filtradas por un registro coloquial, con la intención de evocar un estilo de vida. Todo ello desemboca en un proceso creciente de desmitificación que afecta, en sucesivos niveles de alcance, a las estrategias retóricas del discurso poético, a la esencia del objeto poético y a los patrones culturales que gobiernan la sociedad occidental tardocapitalista.

\subsection{La publicidad como gancho}

En algunas ocasiones, la poesía tiende a desacralizarse al vincularse con los recursos expresivos de la publicidad (Bagué Quílez y Rodríguez Rosique 2020). Esta herramienta se intensifica si, además, se añade a la receta un componente oral. Prueba de ello es «Una moneda para los músicos» (Estudio de lo visible, 2007), de Mariano Peyrou, cuyo primer verso establece ya una interpelación al destinatario con resonancias publicitarias:

\section{UNA MONEDA PARA LOS MÚSICOS}

Que levanten la mano los que estén a favor de no viajar nunca a ningún lado. Aquí 
huele a hierba recién cortada y el clima cambia con rapidez. Si uno se queda en casa con suficiente insistencia, la escalera puede llegar al extranjero, por no mencionar que estoy oyendo hablar en alemán ni las exposiciones itinerantes. Han vaciado el lago, todo es diferente excepto el lago, que sigue siendo una enorme extensión homogénea pero de tierra. Cambia el paisaje. Las estatuas son diferentes, los árboles, la gente, y sobre todo las barcas. Ya deberías ponerte la camisa.

En efecto, el poema arranca en clave oral mediante un inserto que remite a un anuncio publicitario. La oralidad se apoya en el uso del que independiente como forma imperativa -«que levanten la mano los que estén a favor / de no viajar nunca a ningún lado»-(Garrido 1999: 3908-3909), que funciona como detonante del poema. Es precisamente esta estructura la que activa un marco publicitario, que se halla frecuentemente en spots comerciales; de hecho, nos retrotrae a la campaña de Coca-Cola Light «Que levante la mano», creada por la agencia de publicidad argentina Santo, y adaptada al ámbito nacional por España Publicis [Imágenes 1 y 2$]^{4}$.

IMAGEN 1.

Campaña de Coca-Cola Light «Que levante la mano»

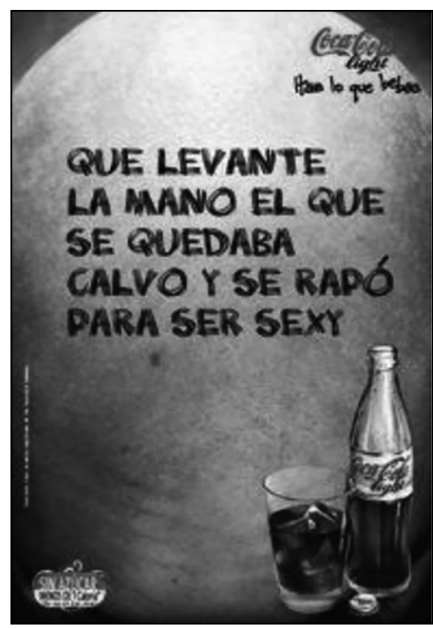

IMAGEN 2.

Campaña de Coca-Cola Light "Que levante la mano»

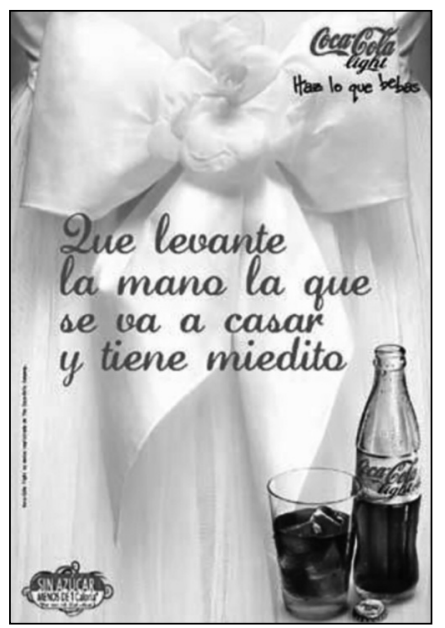

${ }^{4}$ Curiosamente, la noticia del lanzamiento de la campaña data del 24 de enero de 2007, y el libro de Mariano Peyrou, según el colofón, se imprimió el 10 de abril del mismo año. 
Un paso más allá se localiza el poema que comienza con «En otras familias» (Odio, 2011), de David Refoyo. En este caso, un fragmento oral transcrito en estilo directo -de hecho, aparece entrecomillado- polemiza con uno de los eslóganes más reconocibles de la marca IKEA:

\section{[EN OTRAS FAMILIAS]}

En otras familias los padres legaban a sus hijos relojes del diecinueve unos gemelos de cuando la guerra un crucifijo amuleto con el que vencer la tuberculosis

En la mía siempre fuimos distintos y el único testamento digno que pasó del bisabuelo -al que mataron en la guerraal abuelo y de este -castrador de sueñosa mi padre

fue la magnífica frase que les otorgaba el poder

«todo lo que hay bajo este techo es mío y si no te gusta ya sabes dónde tienes la puerta»

Supe dónde estaba la puerta y me independicé con la rabia sincera de los niños malos

Ahora sobre la puerta de mi casa hay un epitafio tallado a navaja

Bienvenidos a la república independiente de mi casa

El cliché comunicativo «y si no te gusta / ya sabes dónde tienes la puerta», insertado en el fragmento en estilo directo, constituye una condicional de enunciación (Montolío 1999: 3685-3689; Rodríguez Rosique 2008: 147150), en la que la relación implicativa se establece entre las circunstancias enunciativas que describe la prótasis y el acto de habla que aparece en la apódosis. La agresividad, en términos de cortesía, de ese extracto contrasta con la calidez doméstica difundida por la compañía. No obstante, ambas 
herramientas inciden en un mismo mensaje: la independencia y la autonomía del individuo frente a los lazos familiares. Ese peculiar paralelismo se expresa poéticamente mediante la calificación que el poeta atribuye a cada uno: si la advertencia del padre se define irónicamente como «magnífica frase», la consigna a la que apela el sujeto certifica la rotundidad de sus convicciones al elevarse a la categoría de un «epitafio tallado a navaja». La autonomía que reivindica el autor se refuerza mediante la modificación del eslogan de IKEA $^{5}$, que pasa de aludir a la segunda persona como forma de invitación («Bienvenidos a la república independiente de tu casa») a delimitar el espacio privado de la primera persona («Bienvenidos a la república independiente de mi casa») [Imagen 3].

IMAGen 3. Campaña de IKEA

«Bienvenido a la república independiente de tu casa»

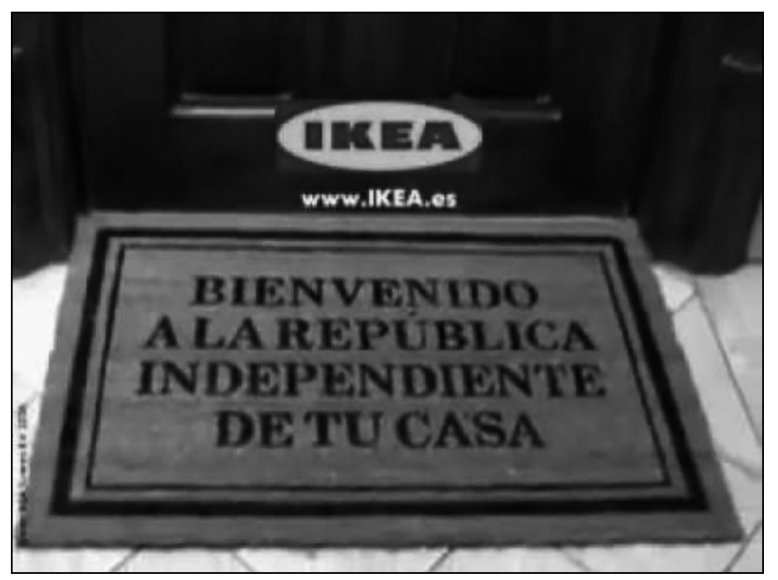

\subsection{La sociedad del espectáculo}

Si en los casos anteriores la oralidad en los textos poéticos aparecía directamente filtrada por la publicidad, en este apartado se presentan otros casos más complejos, determinados por la existencia de un formato previo

${ }_{5}^{5}$ Aunque el eslogan original de la campaña era «Bienvenido a la república independiente de tu casa", algunos productos de la propia marca jugaban con la plantilla con una finalidad distinta, vinculada al marketing: era posible encontrar felpudos con la leyenda «Bienvenido a la república independiente de mi casa» para provocar que el futuro comprador sintiera esos productos como propios. Para la rentabilidad del uso de la segunda persona en el discurso publicitario, pueden verse Serrano y Hernández Toribio (2015) y Aijón Oliva (2019). 
-una entrega de premios, una noticia de impacto mundial o la dinámica de las citas rápidas- de carácter oral. El formato ritualizado de esos poemas remite a la sociedad de consumo a través de un proceso de espectacularización del que también hace uso la publicidad. No obstante, si el objetivo de la propaganda comercial es persuasivo, la finalidad del discurso lírico reside en la desmitificación del objeto poético: la vida, la poesía y el amor aparecen devaluados por los estereotipos de la sociedad de consumo.

En «La gala» (Poemas pequeñoburgueses, 2016), de Juan Bonilla, la desmitificación de un sujeto autoral de mediana edad se acoge al formato espectacular por excelencia: la gala de entrega de los «Oscar», por la que desfila la flor y nata del star system hollywoodiense.

\section{LA GALA}

Vamos a celebrar el medio siglo

a lo grande, como una gala de los Oscars:

mejores efectos especiales para cualquiera de los nombres del autor de todo esto, Dios o los dioses o el Azar, la Nada, el Sin Porqué, y que suba a recoger el premio cualquiera de sus criaturas,

mejor banda sonora el mar de Cádiz, que pronuncia mi infancia en cada ola,

mejor canción el «Vamos, Xerez, vamos» interpretado por el estadio de Chapín la tarde en que nuestro equipo subió a primera división,

mejor papel secundario femenino, para mi madre, la voz que me despertaba con mi nombre cada día y me miraba a los ojos cuando se murió contándome un secreto que no he sabido descifrar,

mejor papel secundario masculino es para Peke él sabe bien por qué y con eso basta,

mejor película de animación es para Explorer que entró como un mensaje una mañana en nuestra casa cuando le abrí al cartero y nos llenó de ronroneos la rutina,

mejor película documental es para La Biblioteca que guarda mil mañanas de búsqueda en locales subterráneos, puestos a la intemperie, rastros de tantas ciudades, y noches de lectura confiadas a la búsqueda de un verso que nos salvase el día, 
mejor hallazgo científico es para el alprazolam, un ejército de soldados químicos que arrasaban angustias y volvían a poner las cosas en su sitio,

mejor guion original es para Agustín García Calvo por enseñarnos que la realidad no es todo lo que hay y que ser es ser y no ser sin que puedan prescindir uno del otro,

mejor guion adaptado es para Maiakovski ${ }^{6}$

por prestarme su vida

y por estar ahí enfrente vigilándome, tan vivo, en el retrato que le hizo Carlos García Alix,

mejor interpretación femenina es para ti, sin duda alguna, trece años de película

que han pasado como un cortometraje,

mejor interpretación masculina

para el terco muchacho que hoy me mira en el espejo

lleno de sueños ambiciosos, caducados, al que he decepcionado tantas veces

sin que haya perdido la esperanza de que alcance a parecerme a lo que él creía merecer, pobre chaval,

mejor película es para «Lo que venga»

pues si algo he aprendido es que del pasado nadie vive

y el futuro,

que lo sabe todo de nosotros,

aún mantiene con ansias, hambre y sed,

esta perplejidad tan simple

de querer seguir rodando

por descubrir que entre lo que me espera

sigue latiendo lo inesperado.

El poema aprovecha la distancia existente entre las superproducciones premiadas y las secuencias de una vida anodina, a las que intenta alzar a la condición de acontecimiento calcando las categorías nominadas (salvo «el mejor hallazgo científico») y singularizándolas a través de la mayúscula inicial («mejor película documental es para La Biblioteca»). La manera de narrar ese acontecimiento, como dicta la esencia del formato, es eminentemente oral, según se observa en una serie de rasgos. Llama la atención el predominio de una sintaxis paratáctica. En ocasiones, los premios «se

${ }^{6}$ El poeta ruso Vladimir Maiakovski es el protagonista de la novela Prohibido entrar sin pantalones (2013), una biografía ficcionalizada por la que Juan Bonilla obtuvo el premio «Mario Vargas Llosa». 
otorgan» respetando las reglas de la sintaxis oracional, excepto por la necesidad del determinante que debería encabezar el sintagma nominal sujeto, que no aparece nunca: «mejor papel secundario es para Peke», «mejor película de animación es para Explorer», etc.). Sin embargo, abunda la yuxtaposición de segmentos sintácticos, a veces introducidos por la preposición para, con o sin coma («mejores efectos especiales para cualquiera de los nombres / del autor de todo esto», «mejor papel secundario femenino, para mi madre»), y otras veces simplemente encadenados ( mejor banda sonora el mar de Cádiz», "mejor canción el "Vamos, Xerez, vamos”»). En estos últimos resulta fundamental la entonación, que obliga a una cesura copiando patrones orales. También aparecen oraciones coordinadas mediante la conjunción copulativa y, que en la mayoría de los casos puede reforzarse pragmáticamente hasta alcanzar otros valores (Levinson 2000: 112-134), como la consecuencia: "él sabe bien por qué y con eso basta», «que arrasaban angustias y volvían a poner las cosas en su sitio», «mejores efectos especiales para cualquiera de los nombres / del autor de todo esto [...] / y que suba a recoger el premio cualquiera de sus criaturas». En este último caso, además, vuelve a aparecer el que independiente con valor imperativo. Desde la perspectiva léxica, sorprende la aposición pobre chaval, que inserta otro giro coloquial en el discurso poético. Y lo mismo sucede, en términos gramaticales, con el segmento constituido por el relativo complejo neutro y el subjuntivo lo que venga, que aporta un valor de indiferencia e inespecificidad propio del registro oral (Cortés Parazuelos 1993; Albelda 2007; RAE 2009: 2515-2516).

A un patrón semejante responde «El gran poema de amor que el mundo llevaba largo tiempo esperando»(Frecuencias, 2012), de Jesús Jiménez Domínguez. En este caso la espectacularización no revierte en la biografía del propio sujeto, sino en su condición de poeta, que queda desmitificada mediante la ruptura de expectativas. El poema se concibe como la respuesta a la pregunta de una interlocutora que le exige «el poema que me debes»; es decir, una composición amorosa que responda a los cánones petrarquistas y que suscriba el tópico quevedesco del «amor constante más allá de la muerte». La segunda parte del poema anuncia la llegada del texto como si fuera un gran acontecimiento, para lo cual se conjuran la naturaleza (hormigas, nubes), la cronología (el meridiano de Greenwich), la filosofía (Heráclito) y la tradición lírica (Coleridge), según se aprecia a continuación:

\section{EL GRAN POEMA DE AMOR \\ QUE EL MUNDO LLEVABA LARGO TIEMPO ESPERANDO}

$[\ldots]$

Hoy, por fin, radios y televisiones de medio mundo interrumpen sus primeras noticias para retransmitirlo. 
La expectación, lógicamente, es máxima; no es para menos. A tal efecto han detenido su flujo las horas de Greenwich, los aeropuertos de Europa, los ríos de Heráclito. Las hormigas allá abajo hacen un alto en su trabajo diario, se paran las fábricas de nubes, el arpa de Coleridge enmudece. Hay redobles y guirnaldas, suenan trompetas, pífanos. Porque aquí llega, aquí está El Gran Poema De Amor Que El Mundo Llevaba Largo Tiempo Esperando:

Como se ha comentado, el efecto desmitificador se concentra en los versos finales. No solo se pregona enfáticamente el nacimiento del poema, sino que este se interrumpe de manera abrupta después de los dos puntos finales, dejando en suspenso lo que el lector esperaba encontrarse: el poema de amor se sustituye así por su mera enunciación, si bien la transcripción en mayúscula de las iniciales en todas las palabras del sintagma confiere transcendencia al referente, de forma semejante a lo que sucedía con las «películas» galardonadas en el poema anterior. A este proceso de desmitificación contribuye el soporte oral del evento. En este sentido, destaca el esquema enumerativo del fragmento, así como el asíndeton -o, de nuevo, la yuxtaposición-, que aportan el dinamismo propio de una retransmisión televisiva o radiofónica «en directo». Como en los grandes acontecimientos, se utilizan estructuras intensificativas -la propia enumeración puede considerarse un rasgo intensificador (Albelda 2007: 74-75)- que incrementan la expectación a través de repeticiones anafóricas, como «porque aquí llega, aquí está», en las que se advierte, asimismo, un proceso de focalización -si hiciésemos la transcripción oral del fragmento, habría que poner aquí en mayúsculas para destacarlo: porque AQUÍ llega / AQUÍ está...- (Gutiérrez Ordóñez 1997; Padilla 2005; RAE 2009: 4660-4663, 2011: 482-488). A ello también ayuda la selección léxica (redobles, guirnaldas, trompetas, pífanos), que activa un marco semántico claramente anacrónico -propio, por ejemplo, del mundo grecorromano o renacentista- para realzar la aparatosa escenografía ligada a la llegada del poema.

Ligeramente distinto resulta el procedimiento discursivo que se observa en «First dates» (Las niñas siempre dicen la verdad, 2018), de Rosa Berbel. El título convoca dos realidades contiguas: la espontaneidad de las citas rápidas y el formato de un programa televisivo de citas a ciegas, estrenado en 2016 y presentado por Carlos Sobera. Del primer marco, el poema copia la dinámica habitual en este tipo de interacciones; si atendemos a lo segundo, la estrategia se complica: el dating show invocado constituiría un ejemplo paradigmático de coloquialización estratégica (Briz 2013; López Serena 2014), donde la interacción conversacional está determinada por el formato, y acaso guionizada. 
Las citas van así.

Nunca sabes qué pueden depararte

Vayan pasando ahora uno por uno.

Más allá de la historia. No contemplamos límites.

Los hombres que ahora son

encuentran a los niños que fueron algún día, o a todos esos hombres que en todos estos siglos, tocaron en silencio.

Por ejemplo, un Heráclito

sentándose a la mesa frente a frente,

fabulador y añejo,

con el borde pedante de Flaubert.

No sé si esto va hacia algún sitio.

Hablan de hobbies, taras y amores desdichados.

De ríos, de clichés, de la mejor novela

nunca escrita. La química no anda.

Tienen poco en común estos dos pájaros.

Heráclito no puede haber oído

de Madame Bovary, pobre de él.

Aunque pudo pensar, cosa rarísima,

sin la sombra alargada de Aristóteles.

Bum.

Al final de la cita, se despiden muy fríos y muy sabios, y prometen no verse nunca más, y se lavan los dientes a conciencia.

Una reunión común, pese a lo extraño: dos hombres disgustados con el tiempo y con el humor negro del destino. Justo así, como en todas las citas de este mundo.

Vayan pasando ahora uno por uno.

Más allá de la historia no hay límites, tampoco explicaciones.

Nadie conoce bien cómo va esto.

Aunque el amor es siempre una cosa muy sucia y anacrónica.

Muy sucia y anacrónica. 
La espectacularización del amor a la que parece remitir el título deriva en el (des) encuentro entre la literatura y la filosofía, encarnadas por Flaubert y Heráclito, respectivamente. A partir de aquí, alternan en el poema dos espacios semánticos (Attardo 2001: 2-8): el de las conflictivas relaciones entre palabra y pensamiento, y el de las complicadas relaciones amorosas en el siglo XXI. A diferencia de los casos anteriores, la oralidad del texto no está puesta al servicio de reflejar la artificiosidad de los discursos ceremoniosos o enfáticos, sino que se encuentra mucho más diseminada. Aparecen, en este sentido, algunos insertos orales, como el «Vayan pasando uno por uno», resaltado en cursiva y repetido en dos ocasiones: en su resonancia oral, puede interpretarse como una invitación a participar en el reality; en su manipulación literaria, se concibe como una interpelación al lector que abre y cierra el desarrollo narrativo del poema. Destaca también la segunda persona con valor impersonal (Gómez Torrego [1992] 2013: 14-15), «Nunca sabes qué pueden depararte», que reproduce el flujo de conciencia del personaje -como yo encubierto- al tiempo que, debido a su valor implicativo y universal, remite a un resorte publicitario ${ }^{7}$. Otros clichés coloquiales que se advierten son algunos adjetivos («borde») y sustantivos («pájaros») calificativos, que designan a Flaubert en el primer caso y a la pareja que conforma con Heráclito en el segundo. En la misma dimensión incide la aposición cosa rarísima, constituida por un sustantivo de contenido léxico muy desgastado, que funciona como encapsulador discursivo (Borreguero 2006; Fuentes 2015), y un superlativo. Finalmente, la inserción de la onomatopeya Bum trunca la linealidad discursiva del poema ${ }^{8}$, al tiempo que aporta cierto carácter intensificador propio de la conversación coloquial (Albelda 2007: 80).

\subsection{La marca como estilo de vida}

La referencia a la publicidad -que en el primer apartado de esta sección se concebía como guiño cómplice y en el segundo como estrategia subyacente en el envase discursivo- se incorpora en los textos recogidos en este apartado desde el propio título. La mención de la marca comercial

\footnotetext{
${ }^{7}$ No en vano la plantilla Nunca sabes $X$ se popularizó como leitmotiv de la película Forrest Gump («La vida es como una caja de bombones. Nunca sabes lo que te va a tocar»). De hecho, el esquema se ha aprovechado en campañas como la de La Caja Roja, de Nestlé, que define la personalidad de los individuos en función del bombón que escogerían (Navarro Almendros 2020).

${ }^{8}$ Un papel semejante desempeñaba la onomatopeya Bang en el poema «A Virginia, madre de dos hijos, compañera de Primaria de la autora» (Chatterton, 2014), de Elena Medel.
} 
pone en marcha una de las funciones principales de la publicidad moderna: no solo patrocinar determinados productos, sino promover estilos de vida (Eguizábal 2007: 121). La activación del conocimiento compartido culturalmente favorece el tipo de desmitificación que hallamos en estos poemas: así, Nescafé se vincula con lo light y saludable, el Corte Inglés encarna los cánones de belleza contemporáneos, y Coca-Cola se asocia a la felicidad familiar.

A este propósito responde «Cleopatra en la sección de baño de El Corte Inglés» (Zonas comunes, 2011), de Almudena Guzmán. En este caso, el ritual de la operación bikini permite parodiar la imagen de la autora -al contrastarla con la enigmática belleza de la emperatriz egipcia- y el emblema del consumismo español ${ }^{9}$ :

\section{Cleopatra}

EN LA SECCIÓN DE BAÑo DE El CORTE INGLÉS

Todos los veranos la misma historia.

La luz áspera del probador, el biquini sobre la braga, los pelos en las piernas.

Estás hecha un cuadro.

De Munch.

La resonancia oral se concentra aquí en la inclusión de la expresión de naturaleza fraseológica (Ruiz Gurillo 1997) y tintes coloquiales «estar hecha un cuadro». La efectividad del poema se sustenta, sin embargo, en la deslexicalización del esquema: no se trata de cualquier cuadro, sino que la alusión a Munch nos lleva a pensar en su obra más famosa (El grito) y a reinterpretar el poema como la descripción distorsionada y expresionista del canon de belleza femenino [Imagen 4]. El grito que ahora casi escuchamos parece más bien el del personaje poético al contemplarse en el

9 La propia autora explicaba la inspiración de su poema en los siguientes términos: «Es, ante todo, una sátira de los reclamos publicitarios que esgrime dicho establecimiento para cada estación del año. Después del "ya es primavera en El Corte Inglés”, llega inexorablemente el "ya es verano" en el ídem [...]. Un día, a punto de someterme a tan difícil examen [la prueba del bikini], me fijé en uno de los carteles que dominaban la fachada de El Corte Inglés, en el que me miraba desafiante, desde su perfección, una modelo con un sucinto bikini, cómo no, y de inmediato me acordé de Cleopatra, que en mi imaginario cinéfilo no tiene el rostro del Liz Taylor sino el de Vivien Leigh, mi Reina del Nilo por excelencia» (Guzmán 2020: 212-213). 
IMAGEN 4. Campaña de El Corte Inglés «Summertime»

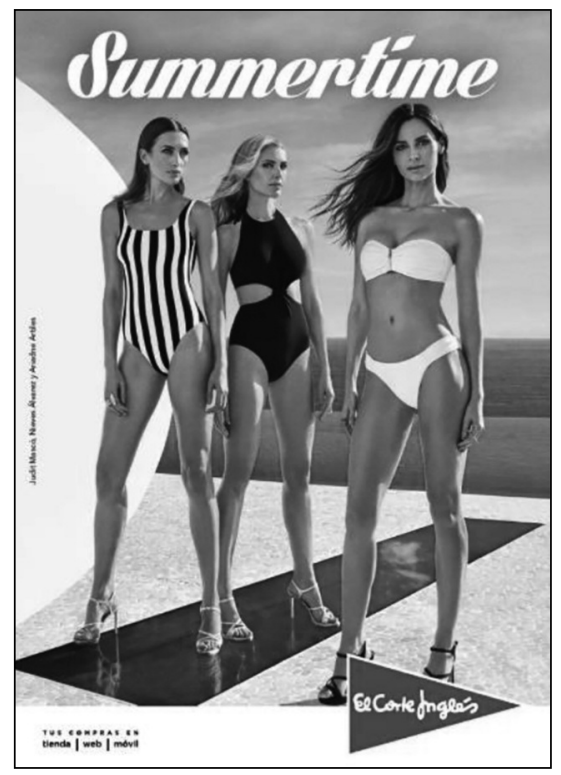

IMAGEN 5.

Campaña de Nescafé descafeinado «El café que sienta bien a todas horas»

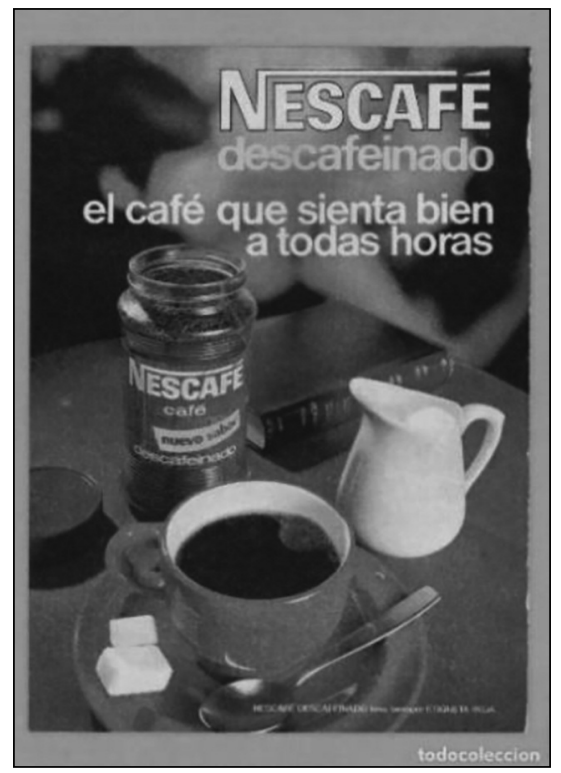

espejo del probador. La desautomatización de expresiones fraseológicas es un recurso habitual como mecanismo irónico y humorístico (Timofeeva 2009), y es igualmente rentable para desplegar estas herramientas en el discurso poético (Rodríguez Rosique y Bagué Quílez 2012; Bagué Quílez y Rodríguez Rosique 2013).

Una desmitificación distinta es la que encontramos en «La vida en Nescafé» (Pertinaz freelance, 2016), de Sergio C. Fanjul, que proyecta «lo descafeinado» sobre distintas esferas de la vida privada y pública: la política, el deporte, la alimentación o la misma poesía. Como resultado, el texto acaba diseñando a un sujeto light sin fuerzas para acometer ninguna revolución, ni la de sus costumbres ni la del proletariado [Imagen 5]:

\section{LA VIDA EN NESCAFÉ}

Son tiempos flexitarianos, de católicos no practicantes.

Yo practico el voto útil y en el fútbol le deseo la victoria siempre al mejor. 


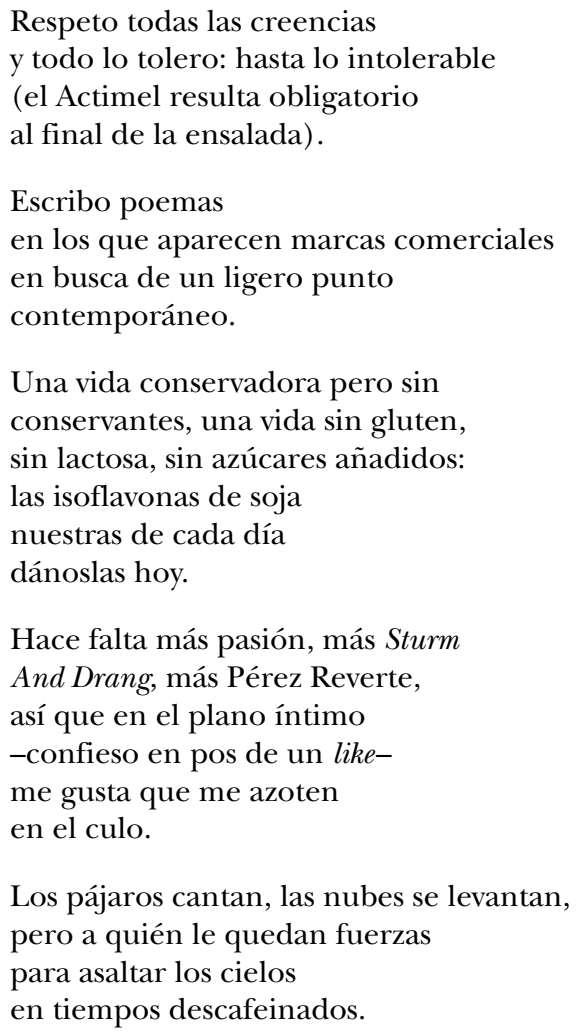

La oralidad emerge aquí en un doble plano. Por un lado, el personaje se apropia, a través de su formulación en primera persona, de extractos orales fácilmente reconocibles que promocionan un modelo de vida descafeinado y que se erigen en consignas de quienes abanderan la neutralidad y la equidistancia para enmascarar su falta de compromiso («yo practico el voto útil», «en el fútbol le deseo / la victoria siempre al mejor», «respeto todas las creencias / y todo lo tolero»). Por otro lado, se incorporan fragmentos intertextuales de naturaleza oral que funcionan en distintos ámbitos: la alusión al Padre Nuestro remite a la liturgia católica («las isoflavonas de soja / nuestras de cada día / dánoslas hoy); el injerto de estribillos infantiles dota de falsa ingenuidad al discurso ( «los pajaritos cantan, las nubes se levantan»); y la expresión «asaltar los cielos», acuñada originalmente por Marx, aparece filtrada en el poema mediante la frase que Pablo Iglesias pronunció en el congreso de Podemos celebrado en 2014.

Otra marca registrada protagoniza «Coca-Cola» (en Poesía completa, 2019), de Manuel Vilas, donde el célebre refresco ayuda a desplegar una suerte de árbol genealógico: 


\section{COCA-COLA}

Acábate la Coca-Cola, no dejes nada.

El hielo con limón y la última gota.

El ruido del cubito ya mermado

en el vaso, acábatela,

porque nadie vendrá,

hasta rompo el hielo

con mis dientes.

La bebí con mi padre

hace casi cincuenta años.

La bebí con mi hijo ayer.

La bebo a solas hoy.

Acábatela, no dejes ni una gota.

De nuevo estamos ante un caso de oralidad fragmentada, que se inserta en el poema a través de un imperativo («Acábate la Coca-Cola», «acábatela»), habitualmente destinado a los niños para instarlos a que apuren su bebida.

Imagen 6. Campaña de Coca-Cola «Estás aquí para ser feliz»

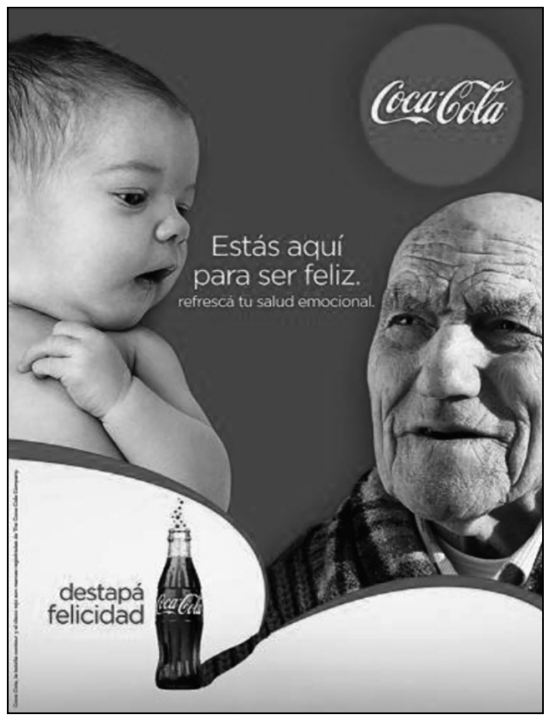

El carácter recurrente de esa instrucción, que se va cumpliendo generación tras generación, configura una auténtica genealogía familiar. La insistencia en terminarse la bebida -reforzada por la intensificación «no dejes nada» (cuantificador universal indefinido de polaridad negativa que agota un parámetro) > «no dejes ni una gota» (término de polaridad negativa y de naturaleza escalar)- puede extrapolarse al consejo moral del carpe diem, que originalmente responde a otra estructura con imperativo («atrapa el día»). Con todo, el conocimiento compartido que activa la marca Coca-Cola, ligado a la felicidad y a los lazos familiares [Imagen 6], contrasta con algu- 
nas de las connotaciones que se pueden extraer del poema, como la intemperie afectiva ( "porque nadie vendrá», «la bebo a solas hoy») o el sentimiento de rabia («hasta rompo el hielo / con mis dientes»). De hecho, no es descartable que el destinatario del último verso sea correferente con el sujeto poemático. De este modo, la épica del fracaso se termina imponiendo a la chispa de la vida (y de la rima).

\section{Conclusión}

La tendencia creciente hacia la coloquialización que ha invadido distintos géneros discursivos (Briz 2013; López Serena 2014; Pons 2014), ha llegado también a la poesía, y quizás para quedarse. A lo largo de este trabajo esperamos haber demostrado que la oralización en los textos poéticos recientes se manifiesta como una especie de sampleado que recoge y reformula insertos orales, en buena medida tamizados por la publicidad -acaso un «verdadero metagénero que permea los medios informativos y culturales, apropiándose de códigos diversos (arte, literatura, técnica) y reinterpretándolos desde una perspectiva utilitaria» (Ponce Cárdenas 2018: 224)-. Esta oralidad mediatizada contribuye a un efecto desmitificador: si en primera instancia el poema se desacraliza al emparentar con los recursos orales que utiliza la publicidad, un segundo paso implicaría una desmitificación del objeto poético a partir de la utilización de un formato envasado que bebe de una oralidad ritualizada; finalmente, una oralidad fragmentada se encarga de invocar los estilos de vida promovidos por determinadas marcas. En suma, junto a la oralidad recreadora -fingida, mimética o simulada- y la oralidad persuasiva -estratégica o simuladora de realidad-, proponemos añadir la categoría de oralidad creadora con finalidad estética para explicar una de las vías de comunicación poética más rentables en las primeras décadas del siglo XXI. 


\section{BIBLIOGRAFÍA}

AjJón Oliva, Miguel Ángel (2019): Constructing Us. The First and Second Persons in Spanish Media Discourse, Berlín y Boston: Walter de Gruyter.

AlbeldA, Marta (2007): La intensificación como categoría pragmática: revisión y propuesta, Fráncfort: Peter Lang.

Attardo, Salvatore (2001): Humorous Texts. A Semantic and Pragmatic Analysis, Berlín y Nueva York: Mouton de Gruyter.

Auden, Wystan Hugh ([1962] 1974): La mano del teñidor, Barcelona: Barral.

Brioschi, Franco y Costanzo Di Girolamo ([1984] 1988): Introducción al estudio de la literatura, Barcelona: Ariel.

Bagué Quílez, Luis y Susana Rodríguez RosiQue (2013): «La ironía en segundo grado: (in)versiones discursivas en la poesía española reciente», Bulletin of Hispanic Studies 90/3, 295-309.

- (2020): «Poemas patrocinados: implicaciones y aplicaciones». En Luis Bagué Quílez y Susana Rodríguez Rosique, Del tópico al eslogan. Discurso, poesía y publicidad, Madrid: Visor, 99-113.

Borreguero, Margarita (2006): «Naturaleza y función de los encapsuladores en los textos informativamente densos (la noticia periodística)», Cuadernos de Filología Italiana 13, 73-95.

BRIZ GÓMEz, Antonio (2000): «Las unidades de la conversación». En Antonio Briz Gómez y Grupo Val.Es.Co. (eds.), Cómo se comenta un texto coloquial, Barcelona: Ariel, 51-80.

- (2013): «Variación pragmática y coloquialización estratégica. El caso de algunos géneros televisivos españoles (la tertulia)». En Catalina Fuentes Rodríguez (ed.), (Des)cortesía para el espectáculo. Estudios de pragmática variacionista, Madrid: Arco/Libros, 89-126.

— y Grupo VAL.Es.Co. (2003): «Las unidades de la conversación: el acto». En José Luis Girón Alconchel (ed.), Estudios ofrecidos al profesor José Jesús de Bustos Tovar, Madrid: Editorial Complutense, 953-968.

— y - (2014): «Las unidades del discurso oral. La propuesta de Val.Es.Co. de segmentación de la conversación (coloquial)», Estudios de Lingüistica del Español 35/1, 11-71.

BRUMMe, Jenny (2008) (ed.): La oralidad fingida: descripción y traducción. Teatro, cómic y medios audiovisuales, Madrid y Fráncfort am Main: Iberoamericana/Vervuert.

- (2012): Traducir la voz ficticia, Berlín: De Gruyter.

CALvi, Maria Vittoria (2019): «Oralización y polifonía en la lengua del turismo 2.0. El caso de las plataformas de reserva hotelera», Norma 9/1, 1-16.

Chafe, Wallace (1994): Discourse, Consciousness and Time. The Flow and Displacement of Conscious Experience in Speaking and Writing, Chicago: The University of Chicago Press. 
Charaudeau, Patrick (2010): «O discurso propagandista: uma tipologia». En Ida Lucia Machado y Renato Mello (eds.), Análises do discurso hoje, vol. 3, Río de Janeiro: Nova Fronteira, 57-78.

Clark, Herbert (1996): Using Language, Cambridge: Cambridge University Press.

Cortés Parazuelos, María Helena (1993): La expresión de la concesividad en español, Tesis Doctoral: Universidad Complutense de Madrid.

Cullell, Diana (2015): «(Re)locating Prestige: Poetry Readings, Poetry Slams and Poetry Jam Sessions in Contemporary Spain», Hispanic Research Journal 16/6, 547-561.

EguizÁBAL, Raúl (2007): Teoría de la publicidad, Madrid: Cátedra.

Ferrer, Eulalio (2002): Publicidad y comunicación, México: Fondo de Cultura Económica.

Fillmore, Charles J. (1981): «Pragmatics and the Description of Discourse». En Peter Cole (ed.), Radical Pragmatics, Nueva York: Academic Press, 143-166.

Fuentes Rodríguez, Catalina (2015): «Pragmagramática de es que: el operador de intensificación», Estudios Filológicos 55, 53-76.

García Negroni, María Marta y Marta Tordesillas Colado (2001): La enunciación en la lengua. De la deixis a la polifonía, Madrid: Gredos.

GARRIDO, Joaquín (1999): «Los actos de habla. Las oraciones imperativas». En Ignacio Bosque y Violeta Demonte (dirs.), Gramática descriptiva de la lengua española, Madrid: Espasa-Calpe, 3879-3928.

GómEZ TORREGO, Leonardo ([1992] 2013): La impersonalidad gramatical: descripción y norma, Madrid: Arco/Libros.

GRICE, H. Paul ([1957] 1989): Studies in the Way of Words, Cambridge (Mass.) y Londres: Harvard University Press.

GutiéRrez ORdóÑEz, Salvador (1997): Temas, remas, focos, tópicos y comentarios, Madrid: Arco/Libros.

- (2002): De pragmática y semántica, Madrid: Arco/Libros.

GuZMÁn, Almudena (2020): «De menhires y mistoles». En Luis Bagué Quílez y Susana Rodríguez Rosique (coords.), Del tópico al eslogan. Discurso, poesía y publicidad, Madrid: Visor, 211-213.

Hidalgo, Antonio (2002): Comentario fónico de textos coloquiales, Madrid: Arco/ Libros.

Jauralde Pou, Pablo (2014): «Poesía española actual en la Red», Ínsula 805-806, 25-28.

Levinson, Stephen C. (1979): «Activity Types and Language». Linguistics 17, 365399.

- (2000): Presumptive Meaning. The Theory of Generalized Conversational Implicature, Cambridge (Mass.) y Londres: The MIT Press.

López SERENA, Araceli (2007): Oralidad y escrituralidad en la narrativa literaria, Madrid: Gredos.

- (2014): «De la oralidad fingida a la oralidad simuladora de realidad. Reflexiones en torno a la coloquialización del discurso como estrategia mediática», Español Actual 102, 37-75.

MANCERA RuEDA, Ana (2009): «La oralidad simulada en la narrativa contemporánea», Verba 36, 419-436. 
MarTíNEZ, José Enrique (1995): «Oralidad y escritura. Poesía oral y poesía escrita», Estudios Humanísticos. Filología 17, 229-244.

MonTOLío, Estrella (1999): «Las construcciones condicionales». En Ignacio Bosque y Violeta Demonte (dirs.), Gramática descriptiva de la lengua española, Madrid: Espasa-Calpe, 3643-3737.

NARBOna JimÉnEZ, Antonio (2009): «Oralidad y escritura, coloquialidad e informalidad», Minervae Baeticae 37, 111-119.

Navarro Almendros, Ana (2020): Argumentación publicitaria de ayer a hoy: formas lingüísticas, deixis y configuración discursiva, Trabajo de Fin de Grado: Universidad de Alicante.

NúÑEZ Ramos, Rafael (1992): La poesía, Madrid: Síntesis.

Padilla García, Xose A. (2005): Pragmática del orden de palabras, Alicante: Universidad de Alicante.

PAZ, Octavio (1971): Los signos en rotación y otros ensayos, Madrid: Alianza.

Ponce Cárdenas, Jesús (2018): «Negroni / California: teselas publicitarias en Aurora Luque y Juan Antonio González Iglesias». En Luis Bagué Quílez (ed.), Cosas que el dinero puede comprar. Del eslogan al poema, Madrid y Fráncfort: Iberoamericana/Vervuert, 223-247.

Pons Bordería, Salvador (2014): «El siglo XX como diacronía: intuición y comprobación en el caso de o sea», Rilce 30/3, 985-1016.

PorTOLÉs, José (2004): Pragmática para hispanistas, Madrid: Síntesis.

REAl ACADEMIA EsPaÑola [RAE] (2009): Nueva gramática de la lengua española. Morfología y sintaxis, Madrid: Espasa-Calpe.

- (2011): Nueva gramática de la lengua española. Fonética y fonología, Madrid: EspasaCalpe.

Rodríguez RosiQue, Susana (2008): Pragmática y gramática. Condicionales concesivas en español. Fráncfort: Peter Lang.

- y Luis Bagué Quílez (2012): «Verso y reverso: teoría pragmática de la ironía y el humor en la poesía española contemporánea», Bulletin Hispanique 114/1, 411-438.

RuIz GuRILlo, Leonor (1997): Aspectos de fraseología teórica española, Valencia: Universidad de Valencia.

SCARANO, Laura (2014): «Poéticas de lo menor en la galaxia global», Ínsula 805806, 19-21.

SEARLe, John R. ([1969] 1980): Actos de habla, Madrid: Cátedra.

SENABRE, Ricardo (1986): Literatura y público, Madrid: Paraninfo.

- (1991): «Poesía y oralidad», Tropelías 2, 193-202.

Serrano, María José y María Isabel Hernández Toribio (2015): ““¿Porque tú lo vales o porque lo vales?” Variación de la segunda persona tú en los mensajes publicitarios», Ibérica 30, 105-128.

Stalnaker, Robert C. (1978): «Assertion». En Peter Cole (ed.), Syntax and Semantics, 9: Pragmatics, Nueva York: Academic Press, 315-332.

Timofeeva, Larissa (2009): «Las unidades fraseológicas». En Leonor Ruiz Gurillo y Xose A. Padilla García (eds.), Dime cómo ironizas y te diré quién eres, Fráncfort: Peter Lang, 193-217.

ZumTHOR, Paul (1983): Introducción a la poesía oral, Madrid: Taurus. 